
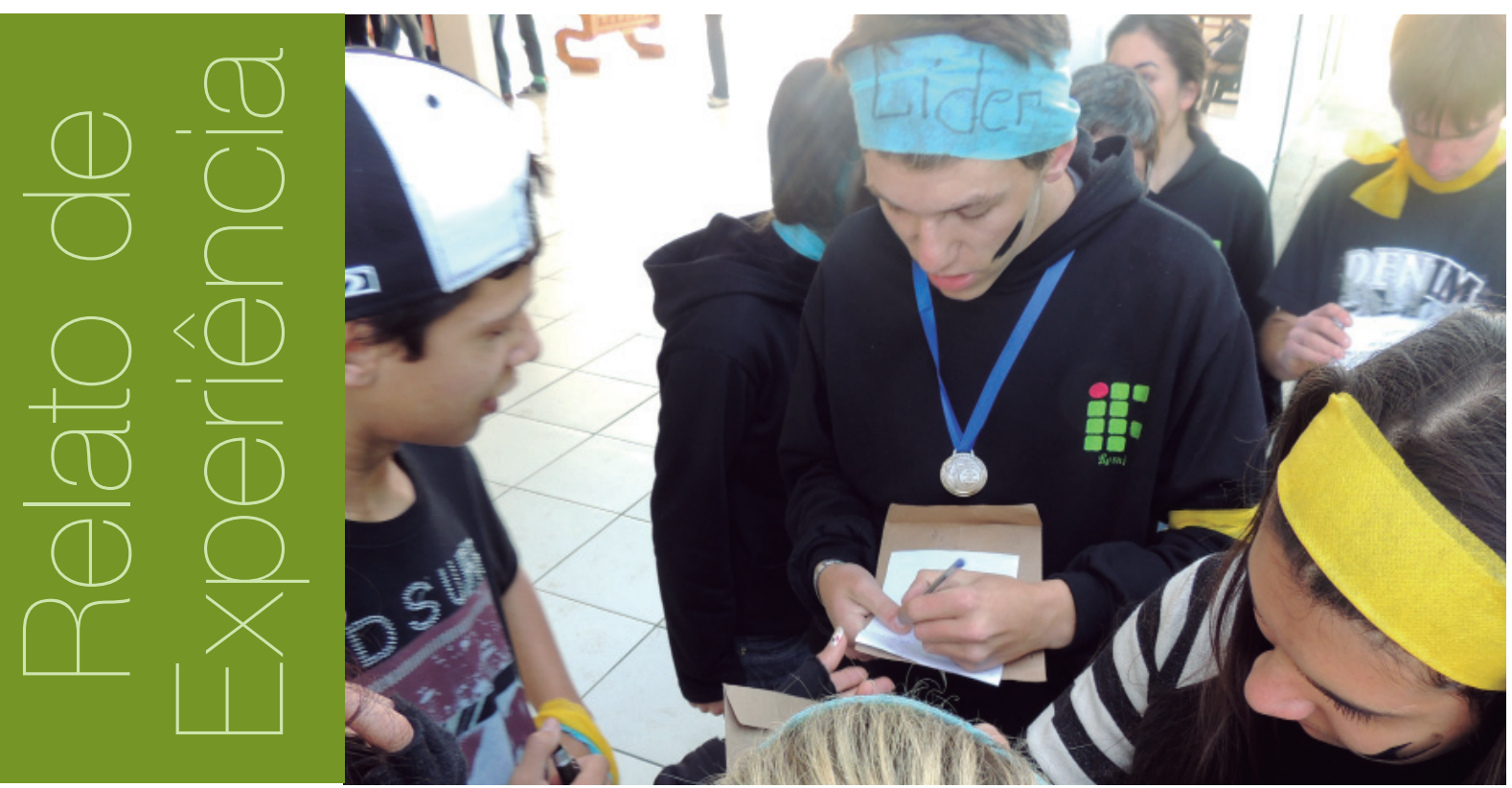

\title{
Gincana estudantil de integração do IFSC Canoinhas
}

\author{
Cassiano Vicente de Lima1 - cassianovdl@gmail.com \\ Ana Cláudia Burmester² - ana.burmester@ifsc.edu.br
}

\section{RESUMO}

A Gincana Estudantil de Integração do IFSC Canoinhas, aprovada pelo edital APROEX - $\mathrm{n}^{\circ}$ 02/2013 - Apoio a pequenos projetos, é um evento de caráter pedagógico, cultural e desportivo, que busca proporcionar a participação das comunidades acadêmica e externa em atividades que desenvolvem diferentes aspectos da formação humana. As provas da Gincana estimulam aprendizagem, consciência cívica, sentimento de pertencimento ao grupo e diversão.

\section{PALAVRAS-CHAVE}

Atividade recreativa. Motivação. Trabalho em equipe.

\section{ABSTRACT}

The student integration competition of IFSC Canoinhas (APROEX nº 02/2013 - Support to small projects) is a pedagogical, cultural and sporting event that aims to promote the participation of the students, teachers, school workers and the community in different activities of human formation. The activities stimulate learning, civic conscience, sense of belonging and amusement.

\section{KEYWORDS}

Recreational activity. Motivation. Teamwork.

\footnotetext{
1 Aluno do curso técnico em Informática do IFSC Canoinhas.

2 Licenciada em Letras Português/Inglês, especialista em Metodologia da Ação Docente. Técnica em Assuntos Educacionais atuante no Departamento de Ensino, Pesquisa e Extensão do IFSC Canoinhas.
} 


\section{Relato de experiência}

0 ingresso de novos alunos no câmpus desencadeou a ideia de uma atividade recreativa para a recepção dos mesmos, assim como a sua integração com a comunidade acadêmica. Pensouse, pois, em uma atividade diferenciada, motivadora e lúdica para fazer com que os alunos se sintam verdadeiros participantes da vida escolar. A Gincana, organizada com 0 apoio de servidores docentes e técnico-administrativos, objetivou proporcionar a integração estudantil e também com a comunidade externa por meio de provas artísticas, culturais, desportivas e de conhecimentos gerais e específicos às áreas de formação técnica do câmpus.

Acredita-se que é importante ter a mente aberta e o pensamento complexo, contextualizando diferentes saberes, e que as pessoas se sintam responsáveis por essa transformação, que é a transformação do mundo (MORIN, 2011). A partir dessa visão, portanto, atividades recreativas não devem ser compreendidas como contraditórias à formação profissional objetivada nos cursos técnicos, mas uma alternativa metodológica que incentive a formação humana e cidadã do profissional. A Gincana, enquanto atividade lúdica e de descontração, deve ser vista como parte do processo de constituição do sujeito, por meio das vivências sociais que a ele proporciona (PEDROZA, 2005 apud SCHMITT et al, 2012).

É importante destacar também o papel das atividades recreativas enquanto momentos de lazer na escola, a qual pode ser o único espaço disponível para tais atividades dentro de algumas comunidades (PACHECO, [200-]). Logo, a escola precisa mostrar-se para a comunidade como espaço de possibilidades diversas, a fim de que haja o desenvolvimento da confiança na instituição e da vontade de fazer parte daquela realidade. Podemos ainda pensar nas atividades lúdicas como possibilidades de crescimento pessoal para os alunos, uma vez que permitem 0 trabalho da expressão oral e artística, o desenvolvimento da autoestima e da autoconfiança e, ao mesmo tempo, o espírito de liderança e de responsabilidade com o grupo no qual se está inserido.

A Gincana foi apresentada aos alunos por meio do lançamento de edital, o qual continha as orientações sobre a formação e inscrição de equipes; constituição da comissão organizadora e da equipe de fiscais; cronograma das atividades e as provas que exigiam preparação prévia. A divulgação do evento se deu por meio de cartazes espalhados pelo câmpus e de explicações para grupos de alunos. Também foi criado um perfil na rede social Facebook. Formaram-se quatro equipes, cada uma com um total de quarenta a cinquenta membros. Os integrantes das equipes eram provenientes de alunos de todos os cursos técnicos e participantes do programa Mulheres Mil. Para cada equipe, foram sorteadas duas cores relacionadas aos Objetivos do Milênio, a partir das quais as equipes seriam identificadas (Fig. 1).

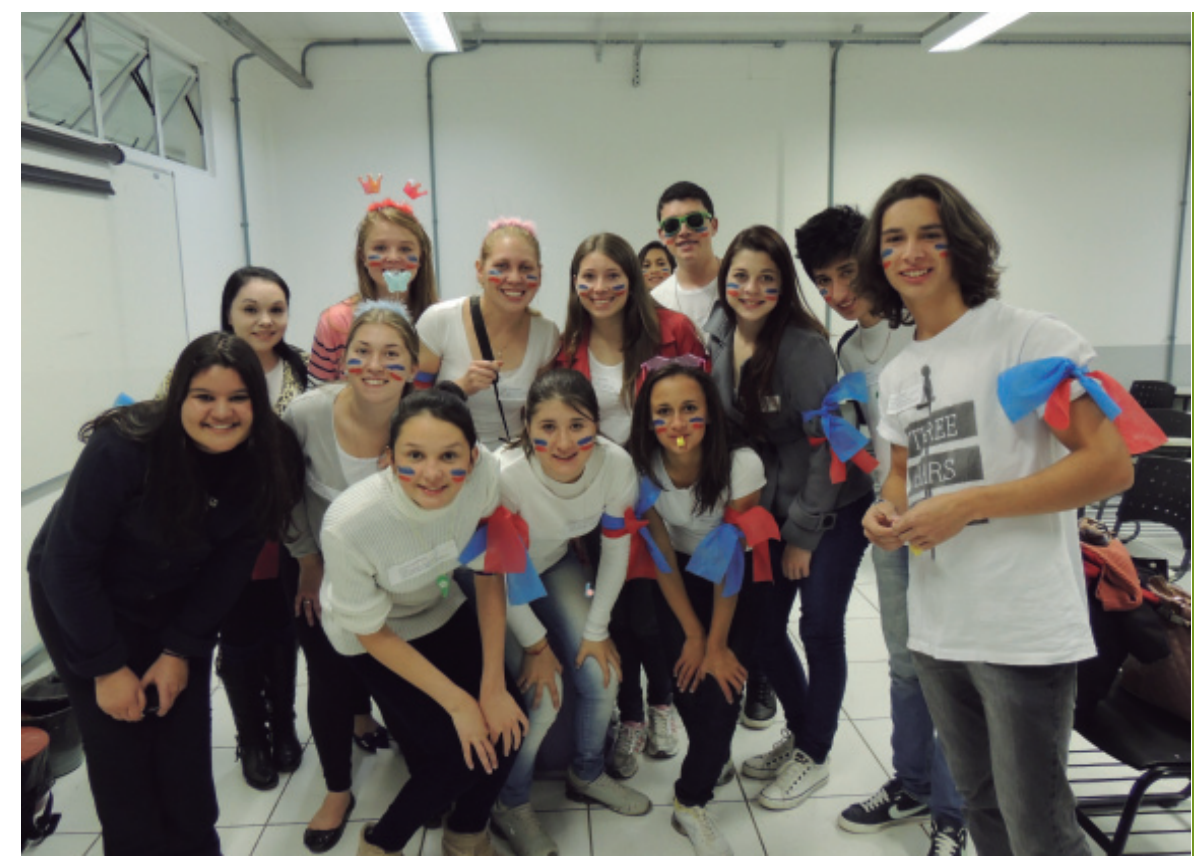

Figura 1: Uma das equipes participantes, com a sua caracterização. 
Na primeira prova, as equipes deveriam convidar pessoas da comunidade para conhecer 0 câmpus. No dia 29 de agosto (sexta-feira), recebemos a visita de 67 pessoas. Neste mesmo dia, as provas artísticas aconteceram no auditório do câmpus, sendo avaliadas por uma equipe de jurados convidados (Fig. 2). Ocorreu a apresentação das equipes, com nome, bandeira, hino e grito de guerra, todos relacionados aos Objetivos do Milênio; além da apresentação, foi feita exposição de paródia sobre a Semana de Ciência e Tecnologia 2013, stand-up sobre educação, desfile ecológico de roupa confeccionada com materiais recicláveis e a arrecadação de materiais escolares para doação à Casa de Passagem Santa Clara, de Canoinhas/SC. Além dessas provas, previamente anunciadas no edital, as equipes foram surpreendidas no dia do evento com provas solicitando apresentações de danças e desafios musicais.

Figura 2: Auditório lotado na noite de sexta-feira, com a mesa de jurados já formada.

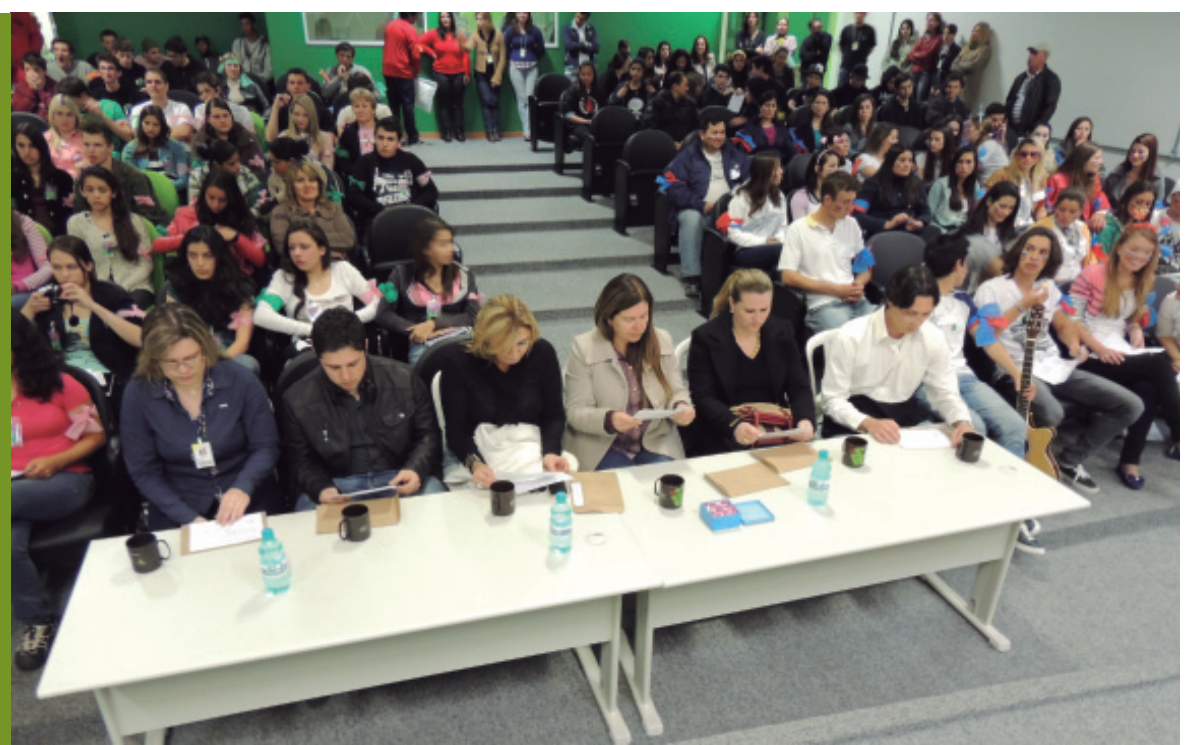

No sábado, os alunos foram recebidos com um café da manhã e dividiram-se para a realização das provas. Ocorreram provas intercaladas durante toda a manhã, solicitando desde a execução de atividades (exemplo: fazer o maior número de embaixadinhas) até provas de conhecimentos, como o Soletrando. Ao mesmo tempo aconteceu a caça ao tesouro (Fig. 3). As equipes recebiam pistas para localizar dez perguntas espalhadas pelo câmpus, todas relacionadas aos cursos técnicos e também de português e matemática. A próxima pista só era fornecida quando a equipe respondesse à pergunta corretamente. Aconteceu ainda o circuito desportivo, com oito estações de atividades físicas. Além disso, foi feita a contagem de garrafas pet arrecadadas para doação à prefeitura municipal, visando colaborar para a decoração natalina.

Figura 3: Uma das equipes participando da Caça ao Tesouro.

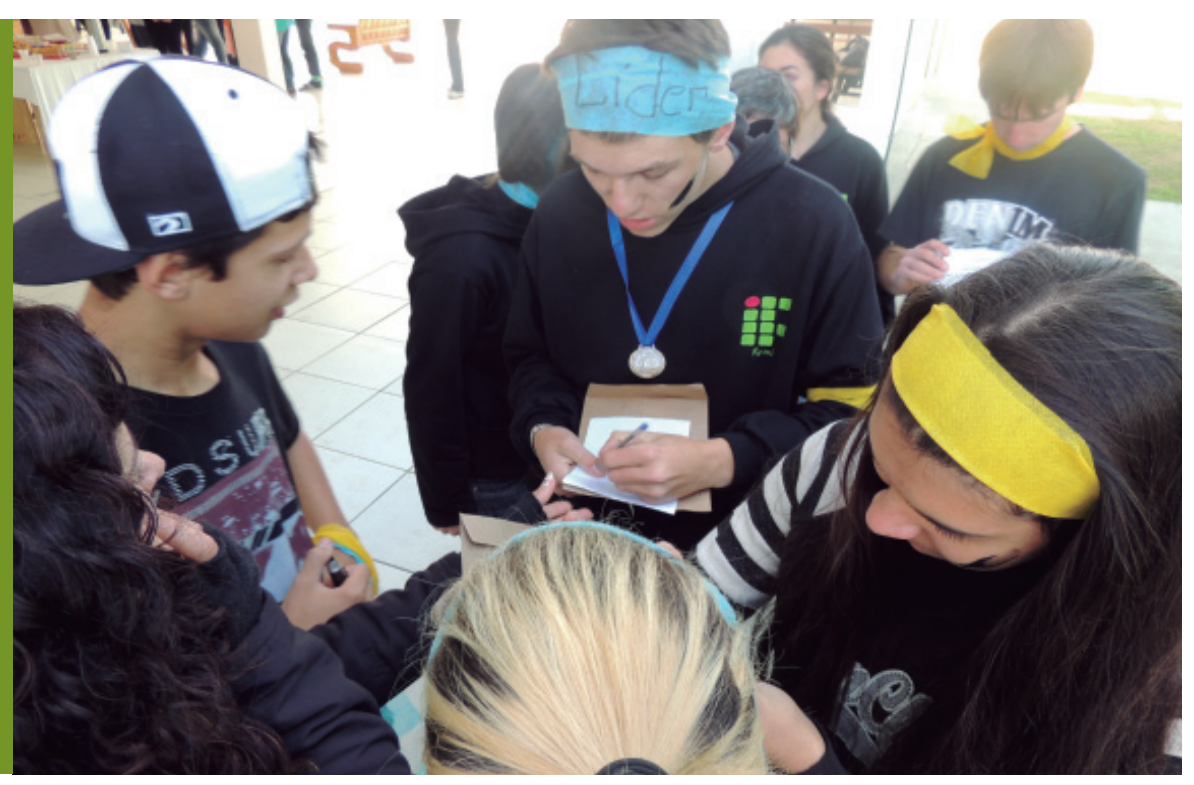


Algumas provas foram premiadas com medalhas e certificados. Em outros dois momentos, a equipe vencedora recebeu um churrasco e o segundo lugar foi premiado com um dia de guloseimas no câmpus, composto por sorvetes e acompanhamentos.

A avaliação do evento ocorreu por meio de questionários contendo perguntas subjetivas e objetivas, aplicados a todos os alunos do câmpus. Obteve-se o retorno de 268 questionários. Foram avaliados os seguintes tópicos: a participação dos alunos, a integração com a comunidade acadêmica, a relevância e o grau de dificuldade das provas propostas. Para compor o questionário, foram inseridas perguntas com a solicitação de elogios, críticas e sugestões bem como um conceito avaliativo para o evento. A partir desse levantamento de dados, foi organizado um momento de discussão com servidores do câmpus, a fim de propor encaminhamentos para uma próxima gincana, em 2014. Os resultados também foram divulgados no Facebook da Gincana.

Essa foi a primeira atividade recreativa do tipo "gincana" realizada no câmpus, e é possível identificar diferentes aspectos que podem ser considerados positivos. A escola realmente se movimentou para a realização do evento, inclusive aproximando-se da comunidade externa. As equipes se mostraram bastante dedicadas a realizar as atividades e, para toda a comunidade acadêmica, foram promovidos momentos de bastante diversão e descontração.

Tanto a partir da observação direta quanto dos dados levantados pelos questionários e das sugestões advindas da reunião avaliativa, podemos destacar alguns itens que merecem ser revistos: a necessidade de se fazer um edital mais claro, a fim de evitarmos dificuldades de interpretação das orientações; a facilidade de se trabalhar com equipes menores e a possibilidade de outras formas de organização das equipes, sabendo que houve relatos de dificuldades em organizá-las pois deveriam contar com alunos dos quatro cursos técnicos. Assim, durante a avaliação, foi sugerida a ideia de formar as equipes com os alunos de um mesmo curso.

Acreditamos que a atividade atingiu, em partes, os objetivos propostos e tem relevância suficiente para se tornar uma atividade permanente no calendário de eventos do câmpus.

\section{Referências}

MORIN, Edgar. Os sete saberes necessários à educação do futuro. 2.ed. São Paulo: Cortez; Brasília, DF: UNESCO, 2011.

PACHECO, Eliezer. Os Institutos Federais: uma revolução na educação profissional e tecnológica. Brasilia, DF: Ministério da Educação, Secretaria de Educação Profissional e Tecnológica, [200-]. Disponível em: <http://portaldoprofessor.mec.gov.br/storage/materiais/0000013531. pdf>. Acesso em: 04 jun. 2014.

SCHMITT, Fernanda Eloisa et al. Gincana recreativa: uma atividade para estimular o conhecimento. Destaques Acadêmicos, Lajeado, RS, v.3, n.4, p.55-61, 2011. Disponível em: <http://www. univates.br/revistas/index.php/destaques/article/view/251> Acesso em: 04 jun. 2014. 